\title{
Desempenho e qualidade da carne de bovinos Nelore e F1 Brangus $x$ Nelore recebendo suplemento com cromo complexado à molécula orgânica na terminação a pasto
}

\author{
Angelo Polizel Neto ${ }^{1}$, André Mendes Jorge ${ }^{1}$, Paulo Sérgio Andrade Moreira ${ }^{2}$, Helen \\ Fernanda Barros Gomes ${ }^{3}$, Rafael Silvio Bonilha Pinheiro ${ }^{1}$
}

\footnotetext{
${ }^{1}$ Faculdade de Medicina Veterinária e Zootecnia - FMVZ/UNESP/Botucatu, SP, Brasil.

2 Instituto Universitário do Norte de Mato Grosso - IUNMAT/UFMT/Sinop, MT, Brasil.

${ }^{3}$ Faculdade de Ciências Agrárias e Veterinárias - FCAVIUNESP/Jaboticabal, SP, Brasil.
}

RESUMO - Objetivou-se avaliar o efeito da suplementação com cromo complexado à molécula orgânica do suplemento no desempenho produtivo, nas características de carcaça e na qualidade da carne de bovinos terminados em regime de pastagem. Foram utilizados 18 bovinos Nelore e 18 F1 Brangus $\times$ Nelore castrados, com 16 meses de idade, mantidos com suplementação mineral protéica, com ou sem cromo complexado à molécula orgânica e abatidos aos 22 meses de idade. O ganho médio diário de peso vivo (GMD) não diferiu entre grupos genéticos, entretanto animais mantidos com suplemento contendo cromo apresentaram maior GMD (494 g) em comparação aos demais (420 g). A adição de cromo orgânico no suplemento não promoveu alterações na área de olho-de-lombo $\left(63,42 \mathrm{~cm}^{2}\right)$ e na espessura de gordura subcutânea do dorso $(5,46 \mathrm{~mm})$ e da garupa $(5,58 \mathrm{~mm})$, tomados por meio do ultra-som. O peso médio de carcaça quente foi $235 \mathrm{~kg}$ e o rendimento médio de carcaça quente, 52,09\%, com superioridade do suplemento contendo cromo (238 kg e 52,9\%) em relação ao controle (231 kg e 51,2\%). Animais Nelore e F1 Brangus $\times$ Nelore apresentam potencial similar de produção de carne a pasto. A suplementação mineral protéica com adição de cromo complexado à molécula orgânica aumenta o ganho de peso e o rendimento de carcaça, mas não influencia os parâmetros qualitativos da carne.

Palavras-chave: carcaça, cruzamentos, maciez, minerais, rendimento, ultra-som

\section{Performance and quality of beef from Nellore and F1 Brangus $\times$ Nellore steers supplied with chromium attached to the organic molecule finished under grass conditions}

\begin{abstract}
The present work was aimed to evaluate the effect of mineral protein supplementation with addition of chromium attached to the organic molecule on the productive performance, carcass traits and beef quality in steers finished under grass conditions. For this, 18 Nellore and 18 F1 Brangus $\times$ Nellore steers were used, with 16 months of average initial age and slaughtered at 22 months, distributed equally into two treatment of mineral protein supplementation with and without addition of chromium attached to the organic molecule. There was no observed difference between genetic groups regarding the average daily gain (ADG). However, animals supplied with chromium showed better ADG (494 g) than control animals (420 g). There was no observed difference between experimental treatments regarding the rib eye area, subcutaneous fat thickness at the back and rump measured through ultrasound, reaching final mean values of $63.42 \mathrm{~cm}^{2} ; 5.46$ and $5.58 \mathrm{~mm}$, respectively. It was observed an average of $235 \mathrm{~kg}$ for hot carcass weight and $52.09 \%$ for dressing percentage, with a superiority for the chromium treatment (238 $\mathrm{kg}$ and $52.9 \%$ ) versus control (231 kg and 51.2\%), and without difference between genetic groups. Nellore and F1 Brangus $\times$ Nellore steers show equal beef production potential under grass conditions. Mineral protein supplementation with chromium attached to the organic molecule increases the weight gain and dressing percentage, not influencing the beef quality parameters evaluated in this study.
\end{abstract}

Key Words: carcass, crossing, mineral, tenderness, ultrasound, yield

\section{Introdução}

Bovinos criados em pastejo estão sujeitos a deficiências minerais e, para corrigir ou reduzir esses efeitos, a suplementação mineral é uma prática necessária para atender às exigências dos animais e garantir adequado suprimento para o desenvolvimento e a produção desejada. Micronutrientes minerais, como cromo e níquel, têm sido 
estudados por participarem no metabolismo de carboidratos, lipídeos e proteínas (Morais, 2001).

O cromo funciona como componente integral e biologicamente ativo do fator de tolerância à glicose (GTF Glucose Tolerance Factor) que potencializa a ação da insulina na célula (Anderson \& Mertz, 1977). O átomo de cromo, do GTF, facilita a interação entre a insulina e os receptores dos tecidos musculares e gordurosos (Mertz, 1987). Assim, o GTF com o $\mathrm{Cr}^{+3}$ é um mensageiro químico que se liga a receptores na superfície das células dos tecidos, estimulando sua capacidade de usar a glicose como combustível metabólico ou armazenar sob a forma de glicogênio (Anderson, 1987).

Como participa no metabolismo energético, o cromo pode influenciar na formação da carcaça dos animais. Mooney \& Cromwell (1997) avaliaram o efeito da suplementação com cromo na carcaça de suínos e verificaram que não houve alteração no ganho de peso e na cobertura de gordura, contudo observaram aumento da área de olhode-lombo e da porcentagem de músculos e decréscimo na porcentagem de gordura total.

Estudos realizados por Luseba (2005) sobre o efeito da suplementação com cromo a bovinos em confinamento relataram melhora nos rendimentos de carcaça e influência no pH final da carne de animais submetidos à suplementação com micronutriente, mas não encontraram diferença entre fonte inorgânica e complexada à molécula orgânica, fato interessante, uma vez que o rendimento de carcaça é o primeiro índice a ser considerado, pois expressa a relação percentual entre o peso do animal e seu valor econômico; e o pH está relacionado à suculência, maciez e coloração da carne (Roça, 2001).

Objetivou-se avaliar o efeito da suplementação protéicomineral com cromo complexado à molécula orgânica no desempenho produtivo, nas características de carcaça, avaliadas por meio de ultra-som, e na qualidade da carne de bovinos Nelore e F1 Brangus $\times$ Nelore terminados em regime de pastagem.

\section{Material e Métodos}

O experimento foi realizado na Agropecuária MAM, município de Poconé, situada a 100 km a Oeste de Cuiabá - Mato Grosso, com bovinos jovens, castrados, na fase de terminação. A área experimental foi subdividida em quatro piquetes, formada uniformemente com Brachiaria brizantha e Brachiaria humidicola, providos de bebedouros e cocho para suplementação cobertos.

Foram utilizados 36 bovinos com 16 meses de idade e peso vivo inicial de $377,3 \pm 18,15 \mathrm{~kg}$ (18 Nelore e 18 F1
Brangus $\times$ Nelore), distribuídos igualmente em dois sistemas de suplementação mineral protéica, com ou sem adição de cromo complexado à molécula orgânica. Antes do início do experimento, os animais foram identificados individualmente, com brinco de rastreabilidade (SISBOV), e receberam um segundo brinco colorido que identificava o lote; além disso, foram tratados contra endo e ectoparasitas e vacinados contra clostridioses (Clostridium sp) e febre aftosa.

Como fonte de cromo foi utilizada levedura de picolinato de cromo e, no suplemento sem este micronutriente mineral, foi adicionado inerte (caulim) na mesma proporção.

O suplemento (Tabela 1 ) foi fornecido diariamente, às $10 \mathrm{~h}$, em quantidades equivalentes a $400 \mathrm{~g} / \mathrm{animal} / \mathrm{dia}$, resultando em ingestão diária de aproximadamente $2 \mathrm{mg} /$ animal nos animais que receberam suplemento com cromo complexado à molécula orgânica.

O experimento teve início no dia 7 de junho de 2006 com a pesagem inicial dos animais, após prévia adaptação de 14 dias, e finalizou no dia 14 de dezembro de 2006 , quando supostamente a média dos animais atingiu o critério de abate (16@ de carcaça),com a pesagem final e com o subseqüente abate dos animais no dia seguinte. Desta forma, o experimento teve duração de 190 dias divididos em seis subperíodos experimentais com duração média de 31 dias.

Tabela 1 - Composição percentual do suplemento, expressa na matéria seca, e níveis de garantia da mistura mineral

\begin{tabular}{ll}
\hline Ingrediente & $\%$ \\
\hline Mistura mineral & 50 \\
Farelo de algodão & 25 \\
Milho triturado & 25 \\
\hline
\end{tabular}

Nível de garantia por kg

de mistura mineral fornecido

Cálcio, g

Fósforo, g

43,00

Fósforo, g

30,00

Sódio, g

Enxofre, g

Cobre, mg

Cobalto, mg

Cromo, mg

Ferro, mg

Iodo, mg

Manganês, mg

Selênio, mg

Zinco, mg

Flúor (máximo), mg

Nitrogênio não-protéico, g

7,80

61,00

19,60

400,00

30,00

10,00

500,00

30,00

NNP equivelente em proteína (máximo), g 421,80

Proteína pruta (mínimo), \% 46,00 
O desempenho produtivo dos animais foi avaliado por meio do peso vivo final (PVf), ganho total de peso vivo (GP) e do ganho médio diário de peso vivo (GMD). Foram realizadas pesagens intermediárias ao fim de cada subperíodo experimental e os animais foram rotacionados entre os piquetes a cada pesagem visando reduzir possíveis efeitos de variação na composição das forrageiras entre piquetes.

O desempenho produtivo também foi avaliado por meio da avaliação das alterações de carcaças dos animais, obtidas por mensurações da área de olho-de-lombo (AOL), em cm² ${ }^{2}$ e da espessura de gordura subcutânea do dorso (EGSD) e da garupa (EGSP), em mm, com ultra-som. Para mensuração da área de olho-de-lombo e da espessura de gordura subcutânea do dorso, foram tomadas imagens entre a $12^{\underline{a}}$ e $13^{\underline{a}}$ coletas, transversal ao músculo Longissimus dorsi, e da espessura de gordura subcutânea do dorso medida no terço médio distal da área de olhode-lombo. Para EGSP, foram tomadas as imagens na junção entre os músculos Gluteos medium e Biceps femoris, após limpeza da pele e com o uso de óleo vegetal como acoplante acústico. O equipamento utilizado foi um Ultra-som Veterinário PIEMEDICAL - Scanner 200, com sonda Sector Curved Array Scanner, modelo 51B04UM02, de $18 \mathrm{~cm}$.

As mensuração da área de olho-de-lombo e das espessuras de gordura subcutânea do dorso e da garupa, por meio do ultra-som, foram realizadas juntamente com a pesagem inicial, no dia 7/6/2006, para obtenção da AOL inicial, da espessura de gordura subcutânea do dorso inicial e EGSP inicial, e com a pesagem final, no dia 14/12/2006, obtendo AOL final, EGSD final eEGSP final, respectivamente. Calculada a diferença entre as mensurações final e inicial, obtiveram-se o ganho de área de olho-de-lombo (GAOL) e os ganhos de espessura de gordura subcutânea do dorso (GEGSD) e da garupa (GEGSP).

$\mathrm{Na}$ determinação das características produtivas da carcaça, foi tomado no dia anterior ao abate, após jejum de sólidos por 12 horas, o peso ao jejum (PJ); e, após o abate e imediatamente antes da entrada da carcaça para a câmara fria, foi tomado o peso de carcaça quente (PCQ), em kg, e calculado o rendimento de carcaça quente (RCQ) pela proporção PCQ/PJ, em porcentagem.

O abate foi realizado em Cuiabá, a 2 horas do local do experimento, no frigorífico comercial São José dos Quatro Marcos, sob Serviço de Inspeção Federal (SIF), segundo o fluxo normal de abate. Imediatamente após a sangria dos animais, as carcaças foram identificadas com etiquetas apropriadas contendo o número de rastreabilidade(SISBOV) e do manejo do animal.
Para melhor avaliação dos dados ultra-sônicos, as mensurações finais foram ajustadas para 100 quilogramas de peso de carcaça quente, segundo recomendações de Luchiari Filho (2000), para obtenção da AOL100, EGSD100 eEGSP100.

Na carcaça foi aferido o pH 2, 10 e 24 horas após o abate dos animais e, como parâmetro influenciador do $\mathrm{pH}$, nesses mesmos intervalos, foram aferidas a temperatura da carcaça, com médias de 25,61; 11,68 e 2,37 ${ }^{\circ} \mathrm{C}$, e da câmara fria, que apresentou valores de $12 ; 10$ e $2^{\circ} \mathrm{C}$, respectivamente. $\mathrm{O}$ pH e a temperatura foram mensurados no músculo Longissimus dorsi, por meio de um peagâmetro termômetro digital, calibrado a cada momento de coleta.

Após 24 horas e antes da liberação das carcaças para desossa, foi coletada a secção do músculo Longissimus dorsi entre a 12 a e $13^{\mathrm{a}}$ costelas de seis carcaças de cada grupo experimental, escolhida ao acaso, para posterior avaliação de alguns parâmetros qualitativos da carne. As amostras, imediatamente após coleta, foram embaladas em sacos plásticos, devidamente identificados, congeladas e posteriormente alocadas em caixas frigoríficas para transporte.

As amostras de carne foram mantidas congeladas por aproximadamente 70 dias em freezer comercial $\left(-18^{\circ} \mathrm{C}\right)$, para avaliação da perda por cozimento, da maciez, coloração e composição centesimal. Para avaliação destes parâmetros qualitativos da carne, foram retiradas duas amostras da seção do músculo Longissimus dorsi, coletadas com 2,5 cm de espessura. Uma das amostras foi destinada à avaliação da perda por cocção e da maciez e a outra para avaliação da coloração e da composição centesimal.

Na avaliação da perda por cocção e maciez, foi adotado o procedimento proposto por Wheeler et al. (1997), com descongelamento sob refrigeração a $5^{\circ} \mathrm{C}$, durante 24 horas, tomando-se o peso inicial da amostra. Sequencialmente, foi introduzido no centro geométrico de cada amostra um termo-acoplador conectado a um termômetro digital, no intuito de monitorar a temperatura interna. As amostras foram levadas ao forno elétrico com temperatura de $250^{\circ} \mathrm{C}$, invertidas quando atingiam temperatura interna de $40^{\circ} \mathrm{C}$, retiradas a $71^{\circ} \mathrm{C}$ e imediatamente pesadas para obtenção do peso final.

A perda por cocção foi encontrada, em porcentagem, pela relação da diferença do peso inicial e final sobre o peso inicial da amostra. Depois de tomados os pesos finais, as amostras foram mantidas até atingirem equilíbrio com a temperatura ambiente e re-embaladas e armazenadas sob refrigeração a $5^{\circ} \mathrm{C}$ durante 24 horas. 
A maciez foi mensurada pela força de cisalhamento, em $\mathrm{kg}$, de oito cilindros de 1,27 cm (meia polegada) de cada amostra, por meio do equipamento mecânico Warner-Bratzler Shear Force, com capacidade de $25 \mathrm{~kg}$ e velocidade do seccionador de $20 \mathrm{~cm} /$ minuto. Ambas as análises foram realizadas no Laboratório de Química e Bioquímica do Instituto de Biociências da UNESP, Campus de Botucatu - São Paulo.

Para avaliação da coloração e composição centesimal, a segunda amostra foi descongelada sob refrigeração a $5^{\circ} \mathrm{C}$, durante 24 horas; depois, foi avaliada a cor por meio do colorímetro digital Minolta Chroma Luminosa, calibrado para um padrão branco em ladrilho, operando em sistema CIE - L*a*b*, no qual L* indica luminosidade e a* e b* são as coordenadas de cromaticidade (de eixo $-\mathrm{a}^{*}-+\mathrm{a}^{*}$ vai de verde a vermelho, $\mathrm{e}-\mathrm{b}^{*}-+\mathrm{b} *$ vai de azul a amarelo). Em seguida, foi coletada uma sub-amostra para avaliação da composição centesimal de acordo com o descrito pela Association of Official Analytical Chemistry (AOAC, 1995), no Laboratório de Tecnologia de Produtos de Origem Animal da Faculdade Ciências Agronômicas da UNESP, Campus de Botucatu - São Paulo.

Em todas as análises estatísticas foi utilizado delineamento inteiramente casualizado, com arranjo fatorial com dois grupos genéticos (Nelore e F1 Brangus $\times$ Nelore) e dois suplementos (com e sem cromo complexado à molécula orgânica).

Na análise dos dados de desempenho, de ultra-som, ultra-sônicos ajustados e dos parâmetros de qualidade de carne, foi utilizada análise de variância com grupo genético, suplemento com cromo e interação grupo genético $\times$ suplemento como fontes de variação. $\mathrm{Na}$ análise dos dados de características produtivas da carcaça (PCQ e RCQ), foi utilizada análise de co-variância com as mesmas fontes de variação e o peso ao jejum como covariável. Os dados foram processados pelo programa SAEG (UFV, 2000), sendo considerando diferença significativa quando $\mathrm{P}<0,05$, em que $\mathrm{P}$ é o nível de significância associado à estatística calculada.

\section{Resultados e Discussão}

Não foi observada interação significativa $(\mathrm{P}>0,05)$ grupo genético $\times$ suplemento para nenhum dos parâmetros avaliados (Tabela 2).

Para o total de animais, 36 observações, foi encontrada média de GMD em todo período experimental de 457 g, superior à observada por Muniz \& Queiroz (1999), que, estudando desempenho de bovinos na recria e terminação, em condições nutricionais e de manejo similares, encontraram em 1.909 observações média geral de GMD de 430 g utilizando diversos grupamentos genéticos.

Não foi encontrada diferença ( $\mathrm{P}>0,05)$ no GMD entre os grupos Nelore (450 g) e F1 Brangus $\times$ Nelore (463 g), contrastando com os dados de Muniz \& Queiroz (1999), que encontraram superioridade para os animais Nelore, com GMD de $446 \mathrm{~g}$ vs $416 \mathrm{~g}$ para os F1 Brangus $\times$ Nelore.

O ganho médio diário foi influenciado apenas pelo suplemento e foi $494 \mathrm{~g}$ maior $(\mathrm{P}<0,05)$ nos animais que receberam suplemento contendo cromo complexado à molécula orgânica em comparação àqueles que receberam o suplemento sem cromo, 420 g, ou seja, aproximadamente $74 \mathrm{~g} /$ animal/dia, totalizando $14,2 \mathrm{~kg}$ de peso vivo no período total, similar aos obtidos por Chang \& Mowat (1992) em estudo sobre o efeito do cromo no desempenho de ruminantes. Esses autores encontraram melhores ganhos nos animais que receberam suplemento com cromo complexado à molécula orgânica em comparação aos animais que não receberam suplemento (790 vs 610 g/animal/dia) nas primeiras semanas após fortes estresses de leilão e transporte. Moonsie-Shageer \& Mowat (1993) também encontraram aumento no ganho de peso diário e na ingestão de alimentos por novilhos submetidos a suplementação com cromo complexado à molécula orgânica em condições de estresse. Esses resultados corroboram os obtidos por Gentry et al. (1999), que avaliando as características de produção influenciadas pela suplementação com cromo, em 32 cordeiros Suffolk, verificaram aumento no ganho de peso diário e no consumo de matéria seca, e melhor

Tabela 2 - Desempenho de bovinos terminados a pasto com suplemento contendo ou não cromo complexado à molécula orgânica

\begin{tabular}{lccccccc}
\hline Parâmetro $^{+}$ & Média & \multirow{2}{*}{ CV } & \multicolumn{2}{c}{ Grupo genético } & & \multicolumn{2}{c}{ Suplemento* } \\
\cline { 4 - 5 } & & & Nelore & F1 Brangus & & Com cromo & Sem cromo \\
\hline PVf (kg) & 464,22 & 2,55 & $462,90 \mathrm{~b} \pm 11,21$ & $465,54 \pm 14,24$ & & $471,33 \pm 13,09 \mathrm{a}$ & $457,10 \pm 12,86 \mathrm{~b}$ \\
GP (kg) & 86,83 & 13,64 & $85,51 \pm 15,10$ & $88,15 \pm 15,40$ & & $93,94 \pm 14,43 \mathrm{a}$ & $79,72 \pm 15,23 \mathrm{~b}$ \\
GMD (g) & 457 & 11,14 & $450 \pm 0,05$ & $463 \pm 0,06$ & & $494 \pm 0,07 \mathrm{a}$ & $420 \pm 0,06 \mathrm{~b}$ \\
\hline
\end{tabular}

* Médias seguidas de letra distintas, na mesma linha, na mesma fonte variação, diferem entre si $(\mathrm{P}<0,05)$.

${ }^{+}$PVf - peso vivo final; GP - ganho de peso vivo; GMD - ganho médio diário de peso vivo.

$\mathrm{CV}$ - coeficiente de variação. 
conversão alimentar no grupo suplementado com cromo e alta proteína.

Diferentemente desse estudo, vários autores não observaram influência da suplementação de cromo no desempenho de animais, como Zanetti et al. (2003), que não verificaram melhora no desempenho de bezerros com suplementação de cromo; e Kegley \& Spears (1996), que não verificaram diferenças no desempenho de novilhos confinados que receberam ou não diferentes fontes de cromo.

Não foi observada influência $(\mathrm{P}>0,05)$ do grupo genético e do suplemento nas características de carcaça avaliadas (Tabela 3).

A área de olho-de-lombo é correlacionada à musculosidade do animal. Neste estudo não foi observada diferença significativa $(\mathrm{P}>0,05)$ para $\mathrm{AOL}$ inicial e final entre os grupos genéticos, tampouco para AOL100 e GAOL, similar aos estudos de Prado et al. (2004), que avaliaram a AOL por ultra-som duas semanas antes do abate de bovinos de diferentes grupamentos genéticos recriados e engordados em condições de pastagem recebendo $1,5 \mathrm{~kg} /$ dia de suplemento protéico e energético, e não encontraram diferença entre animais Nelore e Brangus, que apresentaram aos 22 meses, respectivamente, $51,46 \mathrm{~cm}^{2}$ e $54,63 \mathrm{~cm}^{2}$. Contudo, esses resultados contrastam com os estudos de Mercadante et al. (1999), que observaram efeito significativo do grupo genético sobre a área de olho-de-lombo, medida por equipamento de ultra-som, ao avaliarem 690 animais de diversos grupamentos genéticos.

A espessura de gordura subcutânea é positivamente correlacionada ao total de gordura corporal e negativamente à porcentagem de cortes desossados (Silva et al., 2006). De forma análoga às medidas de área de olho-delombo, não foram observadas diferenças estatísticas
$(\mathrm{P}>0,05)$ entre os grupos genéticos avaliados, quanto às características EGSD inicial e final, e EGSP inicial e final, assim como não foram observadas diferenças $(P>0,05)$ para EGSD100 e EGSP100, e para os GEGSD e GEGSP.

Esses resultados divergem, e foram superiores aos relatados por Prado et al. (2004), que observaram diferença significativa para espessura de gordura subcutânea, mensurada por imagens ultra-sônicas na $13^{\underline{a}}$ costela, entre animais Nelore e Brangus (1,29 e 2,33 mm, respectivamente).

Esses dados também diferem dos encontrados por Taylor (1994), que mostraram que animais com maior grau de sangue de grupo genéticos de tamanho corporal pequeno ou médio, como Brangus (5/8 Angus + 3/8 Brahman), tendem a atingir maturidade e acabamento mais precoces.

Entre os animais que receberam suplemento contendo ou não cromo complexado à molécula orgânica, não houve diferença significativa $(\mathrm{P}>0,05)$ para a AOL inicial e final, nem para AOL100 e GAOL. De forma similar a este estudo, Kitchalong et al. (1995), em cordeiros Suffolk em crescimento recebendo dieta de confinamento à base de milho e caroço de algodão, sem e com 250 ppb de tripicolinato de cromo (cromo complexado à molécula orgânica), não observaram diferença na área de olho-de-lombo nem no ganho de peso diário.

Diferentemente, Gentry et al. (1999) avaliaram o efeito da suplementação de cromo complexado à molécula orgânica nas modificações de carcaça de cordeiros Suffolk e observaram no grupo de animais que receberam alimentação com baixa proteína aumento na área de olho-de-lombo de 15 para $17,1 \mathrm{~cm}^{2}$ nos animais que receberam suplemento com esse micronutriente.

A deposição de gordura de cobertura não diferiu $(P>0,05)$ entre os suplementos, assim, a suplementação com

Tabela 3 - Características de carcaça, avaliadas por ultra-som, de bovinos terminados a pasto com suplemento contendo ou não cromo complexado à molécula orgânica

\begin{tabular}{|c|c|c|c|c|c|c|}
\hline \multirow[t]{2}{*}{ Parâmetro $^{+}$} & \multirow[t]{2}{*}{ Média } & \multirow[t]{2}{*}{$\mathrm{CV}$} & \multicolumn{2}{|c|}{ Grupo genético } & \multicolumn{2}{|c|}{ Suplemento } \\
\hline & & & Nelore & F1 Brangus & Com cromo & Sem cromo \\
\hline AOLi & 56,21 & 12,51 & $55,36 \pm 6,23$ & $57,05 \pm 7,19$ & $56,57 \pm 7,34$ & $55,85 \pm 6,16$ \\
\hline AOLf100 & 27,22 & 11,78 & $26,66 \pm 3,58$ & $27,79 \pm 2,65$ & $26,62 \pm 2,94$ & $27,82 \pm 3,35$ \\
\hline GAOL & 7,20 & 45,88 & $7,56 \pm 6,83$ & $6,82 \pm 4,45$ & $7,74 \pm 6,49$ & $6,65 \pm 4,89$ \\
\hline EGSDi & 3,17 & 22,89 & $2,99 \pm 0,57$ & $3,34 \pm 0,84$ & $2,98 \pm 0,57$ & $3,36 \pm 0,84$ \\
\hline GEGSD & 2,28 & 43,31 & $2,51 \pm 0,82$ & $2,05 \pm 1,14$ & $2,47 \pm 0,94$ & $2,09 \pm 1,07$ \\
\hline EGSPi & 3,35 & 21,38 & $3,19 \pm 0,57$ & $3,50 \pm 0,79$ & $3,26 \pm 0,73$ & $3,43 \pm 0,67$ \\
\hline EGSPf & 5,58 & 20,04 & $5,56 \pm 1,23$ & $5,60 \pm 0,96$ & $5,38 \pm 1,05$ & $5,78 \pm 1,11$ \\
\hline EGSPf100 & 2,39 & 19,79 & $2,36 \pm 0,55$ & $2,42 \pm 0,41$ & $2,24 \pm 0,42$ & $2,54 \pm 0,50$ \\
\hline GEGSP & 2,24 & 52,15 & $2,38 \pm 1,18$ & $2,09 \pm 1,09$ & $2,11 \pm 1,18$ & $2,36 \pm 1,10$ \\
\hline
\end{tabular}

${ }^{+}$AOLi, AOLf, AOL100 e GAOL - área de olho-de-lombo inicial, final e final ajustada para 100 kg de carcaça quente, e ganho de área, em cm². EGSDi, EGSDf, EGSD100 e GEGSD - espessura de gordura subcutânea do dorso inicial, final e final ajustada para $100 \mathrm{~kg}$ de carcaça quente, e ganho de espessura, em mm. EGSPi, EGSPf, EGSP100 e GEGSP - espessura de gordura subcutânea da garupa inicial, final e final ajustada para $100 \mathrm{~kg}$ de carcaça quente, e ganho de espessura, em mm.

CV - coeficiente de variação. 
cromo complexado à molécula orgânica não influenciou a deposição subcutânea de gordura, o que contraria os resultados descritos por Kitchalong et al. (1995) e Mooney \& Cromwell (1997), que observaram redução na deposição de gordura com a suplementação com cromo complexado à molécula orgânica.

Os valores médios de área de olho-de-lombo ajustada para $100 \mathrm{~kg}$ de carcaça quente são inferiores aos sugerido por Luchiari Filho (2000), que recomenda para se ter bom rendimento de cortes o valor mínimo de $29 \mathrm{~cm}^{2} / 100 \mathrm{~kg}$ de carcaça quente, enquanto o valor médio para esse estudo foi de $27,22 \mathrm{~cm}^{2}$. E para se manter boa proporção de gordura na carcaça, esse autor recomenda que a cobertura de gordura deve ser de 2 a 2,5 mm/100 kg de carcaça quente. O valor observado para este estudo foi em torno de 2,33 $\mathrm{mm}$ para espessura de gordura subcutânea do dorso e 2,39 mm para EGSP.

O peso em jejum foi de $451,16 \pm 13,82 \mathrm{~kg}$, utilizado como co-variavél, o peso de carcaça quente, de 235,01 $\pm 11,05 \mathrm{~kg}$, e o rendimento de carcaça de $52,09 \pm 1,97 \%$ (Tabela 4). Os valores médios de peso e rendimento de carcaça quente deste estudo foram inferiores aos observados por Santos et al. (2002), que, em condições similares de pastagens com diversos níveis de suplementação, encontraram 246,3 kg de peso de carcaça quente e 53,6\% de rendimento de carcaça quente para bovinos F1 Nelore $\times$ Limousin. Entretanto, o peso de carcaça quente obtido neste trabalho foi superior aos de 217,5 kg observado por Zervoudakis et al. (2001) em bovinos a pasto recebendo suplemento no início do período das águas, contudo com semelhante RCQ (52,2\%).

As características produtivas da carcaça não diferiram $(\mathrm{P}>0,05)$ entre grupos genéticos nem entre os suplementos, mas houve diferença estatística $(\mathrm{P}<0,05)$ entre os resultados obtidos com e sem adição de cromo complexado à molécula orgânica ao suplemento.

Na comparação entre grupos genéticos, os resultados deste estudo diferem dos obtidos por Galvão et al. (1991), que, trabalhando com animais mestiços oriundos de cruzamento de Nelore com raças de corte européias, verificaram que os animais mestiços apresentaram os melhores rendimentos de carcaça. O mesmo foi observado por Restle et al. (2000) em animais com diferentes graus de sangue entre Nelore e Charolês. Esses autores concluíram que houve melhores rendimentos de carcaça nos animais Nelore, mas ambos os experimentos foram realizados com terminação em confinamento, com cruzamentos de Nelore com raças continentais.

O peso e o rendimento de carcaça quente diferiram significativamente entre os suplementos $(\mathrm{P}<0,05)$ e foram maiores para os animais que receberam suplemento com cromo complexado à molécula orgânica.

Esse resultado está de acordo com os encontrados por Pollard \& Richardson (1999), que observaram efeito positivoda suplementação de 0,2 ppm de cromo complexado à molécula orgânica sobre o rendimento de carcaça de bovinos de corte em confinamento. Entretanto, é contrário aos encontrados por Luseba (2005), que não notou diferença no rendimento de carcaça quente em bovinos confinados com suplemento contendo cromo, e Chang \& Mowat (1992), que relataram não haver influência da suplementação com cromo levedura ou com cromo complexado à molécula orgânica nas características de carcaça de bovinos.

Não foi observada nenhuma diferença $(P>0,05)$ entre os suplementos (Tabela 5). Os valores encontrados estão dentro do esperado para se obter carne de qualidade, que

Tabela 4 - Peso e rendimento de carcaça quente de bovinos terminados a pasto com suplemento contendo ou não cromo complexado à molécula orgânica

\begin{tabular}{|c|c|c|c|c|c|c|}
\hline & \multirow[t]{2}{*}{ Média } & \multirow[t]{2}{*}{$\mathrm{CV}$} & \multicolumn{2}{|c|}{ Grupo genético } & \multicolumn{2}{|c|}{ Suplemento* } \\
\hline & & & Nelore & F1 Brangus & Com cromo & Sem cromo \\
\hline Peso de carcaça quente (kg) & 235,01 & 3,42 & $236,91 \pm 11,66$ & $233,09 \pm 10,50$ & $238,76 \pm 8,60 a$ & $231,25 \pm 10,93 b$ \\
\hline Rendimento de carcaça quente (\%) & 52,09 & 3,41 & $52,51 \pm 1,81$ & $51,68 \pm 2,02$ & $52,92 \pm 1,75 a$ & $51,26 \pm 1,86 b$ \\
\hline
\end{tabular}

*Médias seguidas de letra distintas na mesma linha e na mesma fonte variação diferem entre si $(\mathrm{P}<0,05)$.

$\mathrm{CV}$ - coeficiente de variação.

Tabela 5 - pH no músculo Longissimus dorsi de bovinos terminados a pasto com suplemento contendo ou não cromo complexado à molécula orgânica

\begin{tabular}{|c|c|c|c|c|c|c|}
\hline \multirow[t]{2}{*}{ Tempo após abate } & \multirow[t]{2}{*}{ Média } & \multirow[t]{2}{*}{$\mathrm{CV}$} & \multicolumn{2}{|c|}{ Grupo genético } & \multicolumn{2}{|c|}{ Suplemento } \\
\hline & & & Nelore & F1 Brangus & Com cromo & Sem cromo \\
\hline 2 horas & 6,80 & 3,80 & $6,82 \pm 0,18$ & $6,78 \pm 0,33$ & $6,77 \pm 0,29$ & $6,83 \pm 0,18$ \\
\hline 10 horas & 6,20 & 4,92 & $6,21 \pm 0,27$ & $6,19 \pm 0,34$ & $6,14 \pm 0,31$ & $6,26 \pm 0,28$ \\
\hline 24 horas & 5,73 & 1,84 & $5,74 \pm 0,10$ & $5,73 \pm 0,12$ & $5,71 \pm 0,11$ & $5,75 \pm 0,10$ \\
\hline
\end{tabular}

CV - coeficiente de variação. 
devem situar entre 5,5 e 5,8 para as carcaças 24 horas post mortem, ou iniciar a redução de pH próximo a 7,0 e após 24 horas estar com pH entre 5,9 - 5,5 (Roça, 2001). O valor médio encontrado para pH24 $(5,73)$ ficou acima de 5,63, encontrado por Aferri et al. (2005). Entre os suplementos com cromo e sem cromo, observou-se redução normal do pH, como descrito por Felício (1997), sem influência da suplementação de cromo complexado à molécula orgânica na curva padrão.

Não foi observada diferença significativa $(\mathrm{P}>0,05)$ entre os suplementos ou os grupos genéticos (Tabela 6).

O valor médio da perda por cocção foi de $22,02 \%$, próximo ao de $21,71 \%$ obtido em estudos realizados por Canesin et al. (2006), com animais recebendo suplemento a pasto, e ao de $21,10 \%$ encontrado por Felício \& Viacava (2000), e inferior aos $25,56 \%$ encontrados por Oliveira (1993) em animais Nelore.

Os valores de maciez avaliada, por meio do Shear Force, foram de $6,53 \mathrm{~kg}$, relativamente alto se comparado ao proposto por Alves et al. (2005), que consideraram carne de boa maciez aquela de valor inferior a 4,5 kg. Esse valor também difere da média encontrada por Johnson et al. (1988) em animais com maior grau de sangue Bos taurus indicus (75\%), que foi de $5,95 \mathrm{~kg}$.

Para coloração da carne, foi encontrada média de 34,12, 17,09 e 1,18 para os espaços $\mathrm{L}^{*} \mathrm{a}^{*} \mathrm{~b}$, respectivamente. O valor de $\mathrm{L}^{*}$ encontrado foi próximo ao de 34,85 relatado por Loxton (1993) para novilhos mestiços Bos taurus indicus criados em sistema de pastejo no norte da Austrália. Os valores de a* foram semelhantes aos descritos por Abularach et al. (1998), que observaram média de 18,08 em tourinhos da raça Nelore; e superior ao valor médio de 11 preconizado por Felício (1999).

O valor de b* (intensidade de amarelo) foi inferior ao de 5,07, proposto por Felício (1999), e abaixo do intervalo de 3,40 a 8,28 sugerido por Abularach et al. (1998), provavelmente em decorrência da baixa quantidade de gordura intramuscular, representada pela porcentagem de extrato etéreo do músculo L. dorsi.

A umidade média do L. dorsi foi de 74,01\%, inferior à média de 75,65\% relatada por Abularach et al. (1998), porém próxima à de 73,88\% encontrada por Abrahão et al. (2005). Os valores de cinzas observados neste trabalho $(1,19 \%)$ foram similares ao observado (próximo de 1\%) por Rodrigues (2007) em animais confinados.

Os valores médios de proteína e extrato etéreo foram 23,89 e $0,90 \%$, respectivamente. O teor de proteína foi próximo ao valor médio de $22,25 \%$ relatado por Rodrigues (2007), superior à porcentagem média de 19,16 encontrada por Abrahão et al. (2005) em diversos acasalamentos de $1 / 2$ e $3 / 4$ Europeu $\times$ Zebu. O teor de extrato etéreo observado ficou abaixo do valor médio de 2,35\% obtido por Costa et al. (2002) em bovinos Red Angus, e do valor de 2,24\% encontrado por Abrahão et al. (2005) em diferentes grupamentos genéticos, assim como inferior ao observado (1,71\%) por Abularach et al. (1998) em 118 bovinos Nelore machos em confinamento, o que pode ser atribuído à menor deposição de gordura intramuscular de bovinos em pastejo.

Tabela 6 - Características do músculo Longissimus dorsi de bovinos terminados a pasto com suplemento contendo ou não cromo complexado à molécula orgânica

\begin{tabular}{|c|c|c|c|c|c|c|}
\hline \multirow[t]{2}{*}{ Característica } & \multirow[t]{2}{*}{ Média } & \multirow[t]{2}{*}{$\mathrm{CV}$} & \multicolumn{2}{|c|}{ Grupo genético } & \multicolumn{2}{|c|}{ Suplemento } \\
\hline & & & Nelore & F1 Brangus & Com cromo & Sem cromo \\
\hline Perda por cocção (\%) & 22,02 & 26,46 & $21,75 \pm 5,36$ & $22,28 \pm 6,70$ & $19,73 \pm 4,86$ & $24,31 \pm 6,14$ \\
\hline Maciez (kg) & 6,53 & 15,72 & $6,39 \pm 0,86$ & $6,67 \pm 1,62$ & $7,03 \pm 1,25$ & $6,04 \pm 1,12$ \\
\hline L* (luminosidade) & 34,12 & 3,45 & $34,30 \pm 0,96$ & $33,95 \pm 1,32$ & $34,15 \pm 1,38$ & $34,10 \pm 1,07$ \\
\hline a* (vermelho) & 17,09 & 7,30 & $16,53 \pm 1,75$ & $17,65 \pm 1,32$ & $17,70 \pm 1,38$ & $16,47 \pm 1,65$ \\
\hline $\mathrm{b}^{*}$ (amarelo) & 1,18 & 23,27 & $1,38 \pm 1,73$ & $0,97 \pm 2,27$ & $0,58 \pm 2,21$ & $1,77 \pm 1,60$ \\
\hline Umidade (\%) & 74,01 & 3,39 & $73,88 \pm 0,98$ & $74,14 \pm 0,97$ & $73,34 \pm 0,32$ & $74,68 \pm 0,87$ \\
\hline Cinza (\%) & 1,19 & 3,32 & $1,17 \pm 0,15$ & $1,22 \pm 0,15$ & $1,12 \pm 0,08$ & $1,26 \pm 0,17$ \\
\hline Proteína (\%) & 23,89 & 4,56 & $23,77 \pm 0,95$ & $23,99 \pm 0,83$ & $24,06 \pm 0,47$ & $23,71 \pm 0,76$ \\
\hline Extrato etéreo (\%) & 0,90 & 30,23 & $0,91 \pm 0,35$ & $0,89 \pm 0,49$ & $0,91 \pm 0,34$ & $0,89 \pm 0,31$ \\
\hline
\end{tabular}

CV - coeficiente de variação.

\section{Conclusões}

Animais Nelore e F1 Brangus $\times$ Nelore apresentam potencial similar de produção de carne de qualidade a pasto.
A suplementação protéico-mineral com adição de cromo complexado à molécula orgânica melhora o ganho de peso e o rendimento de carcaça e não influencia os parâmetros qualitativos da carne. 


\section{Literatura Citada}

ABRAHÃO, J.J.S.; PRADO, I.N.; PEROTTO, D. et al. Características de carcaça e da carne de tourinhos submetidos a dietas com diferentes níveis de substituição do milho por resíduo úmido do extrato da fécula de mandioca. Revista Brasileira de Zootecnia, v.34, n.5, p.1640-1650, 2005.

ABULARACH, M.L.S.; ROCHA, C.E.; FELICÍO, P.E. Característica de qualidade do contra-filé (m. L. dorsi) de touros jovens da raça Nelore. Ciência e Tecnologia de Alimentos, v.18, n.2, p.205-210, 1998.

AFERRI, G.; LEME, P.R.; SILVA, S.L. et al. Desempenho e características de carcaça de novilhas alimentadas com dietas contendo diferentes fontes de lipídios. Revista Brasileira de Zootecnia, v.34, n.5, p.1651-1658, 2005.

ALVES, D.D.; GOES, R.H.T.B.; MACEDO, A.B. Maciez da carne bovina. Ciência Animal Brasileira, v.6, n.3, p.135-149, 2005.

ANDERSON, R.A. Trace elements in human and nutrition. New York: Academic Press, 1987. 225p.

ANDERSON, R.A.; MERTZ, W. Glucose tolerance factor: an essential dietary agent. Trends in Biochemical Sciences, v.2, n.2, p.277-279, 1977.

ASSOCIATION OF OFFICIAL ANALYTICAL CHEMISTRY AOAC. Official methods of analysis. 16.ed. Arlington: AOAC International, 1995. 1025p.

CANESIN, R.C.; BERCHIELLI, T.T.; ANDRADE, P. et al. Características da carcaça e da carne de novilhos mantidos em pastagem de capim Marandu submetidos a diferentes estratégias de suplementação. Revista Brasileira de Zootecnia, v.35, n.6, p.2398-2375, 2006.

CHANG, X.; MOWAT, D.N. Supplemental chromium for stressed and growing feeder calves. Journal of Animal Science, v.70, p.559-565, 1992.

COSTA, E.C.; RESTLE, J.; BRONDANI, I.C. et al. Composição física da carcaça, qualidade da carne e conteúdo de colesterol no músculo Longissimus dorsi de novilhos Red Angus superprecoce, terminados em confinamento e abatidos em diferentes pesos. Revista Brasileira de Zootecnia, v.31, n.1, p.417-428, 2002 (supl.).

FELÍCIO, P.E. Fatores ante e post mortem que influenciam na qualidade da carne bovina. In: SIMPÓSIO SOBRE PECUÁRIA DE CORTE, 4., 1996, Piracicaba. Anais... Piracicaba, Fundação de Estudos Agrários "Luis de Queiroz", 1997. p.79-97.

FELÍCIO, P.E. Qualidade da carne bovina: características físicas e organolépticas. In: REUNIÃO ANUAL DA SOCIEDADE BRASILEIRA DE ZOOTECNIA, 36., 1999, Porto Alegre. Anais... Porto Alegre: Sociedade Brasileira de Zootecnia, 1999. (CD-ROM).

FELÍCIO, P.E.; VIACAVA, C. Programa da ACNB para a carne Nelore. In: SIMPÓSIO NELORE, Ribeirão Preto. Anais... Ribeirão Preto: Associação de Criadores de Nelore do Brasil, 2000. p.65-69. (CD-ROM).

GALVÃO, J.G.C.; FONTES, C.A.A.; PIRES, C.C. et al. Característica e composição física da carcaça de bovinos não castrados, abatidos em três estágios de maturidade, de três grupos raciais. Revista Brasileira de Zootecnia, v.20, n.5, p.502-512, 1991.

GENTRY, L.R.; FERNANDEZ, J.M.; WARD, T.L. et al. Dietary protein and chromium tripicolinate in Suffolk Wether lambs: effects on production characteristics, metabolic and hormonal responses, and immune status. Journal of Animal Science, v.77, p.1284-1294, 1999.

JOHNSON, D.D.; LUNT, D.K.; SAVELL, J.W. et al. Factors affecting carcass characteristics and palatability of young bulls. Journal of Animal Science, v.66, p.2568-2577, 1988.

KEGLEY, E.B.; SPEARS, J.W. Immune response and disease resistance of calves feed chromium nicotinic acid complex or chromium cloride. Canadian Journal of Dairy Science, v.79, p.1278-1283, 1996.
KITCHALONG, L.; FERNANDEZ, J.M.; BUNTING, L.L. et al Influence of chromium tripicolinate on glucose metabolism and nutrient partitioning in growing lambs. Journal of Animal Science, v.73, p.2694-2705, 1995.

LOXTON, I.D. The influence of animal nutrition on the quality of meat from Bos indicus cross-bred steers in Northern Australia. In: THE AUSTRALIAN MEAT INDUSTRY RESEARCH CONFERENCE, 1993, Sydney. Anais... Sydney: CSIRO, Austrália. 1993. p.1-13.

LUCHIARI FILHO, A. Pecuária da carne bovina. 1.ed. São Paulo: Luchiari Filho, 2000. p.134.

LUSEBA, D. Effect of selenium and chromium on stress level, growth performance, selected carcass characteristics and mineral status of feedlot cattle. 2005. 214f. These (Doctor of Philosophy in Veterinary Science) - Faculty of Veterinary Science, University of Pretoria, Pretoria, 2005.

MERCADANTE, M.E.; CYRILLO, J.N.S.G.; SILVA, L. et al. Medidas de ultra-som de área de olho de lombo e espessura de gordura de cobertura em bovinos em prova de ganho de peso. In: REUNIÃO ANUAL DA SOCIEDADE BRASILEIRA DE ZOOTECNIA, 36., 1999, Porto Alegre. Anais... Porto Alegre: Sociedade Brasileira de Zootecnia, 1999. (CD-ROM).

MERTZ, W. Trace elements in human and nutrition. London: Academic Press, 1987. v.1, 355p.

MOONEY, K.W.; CROMWELL, G.L. Efficacy of chromium picolinate and chromium as potential carcass modifiers in swine. Journal of Animal Science, v.75, p.2661-2671, 1997.

MOONSIE-SHAGEER, S.; MOWAT, D.N. Effect of level supplemental chromium on performance, serum constituents, and immune status of stress feeder calves. Journal of Animal Science, v.71, n.1, p.232-238, 1993.

MORAIS, S.S. Novos microelementos minerais e minerais quelatados na nutrição de bovinos. Campo Grande: Embrapa Gado de Corte, 2001. 11p. (Documentos, 119).

MUNIZ, C.A.S.D.; QUEIROZ, S.A. Avaliação de características de crescimento pós-desmama de animais Nelore puros e cruzados no Estado do Mato Grosso do Sul. Revista Brasileira de Zootecnia, v.28, n.4, p.713-720, 1999.

OLIVEIRA, A.L. Efeito do peso de abate no rendimento de carcaça e qualidade de carne de novilhos nelore e mestiços Canchin x Nelore. 1993. 130f. Dissertação (Mestre em Tecnologia de Alimentos) - Faculdade de Engenharia de Alimentos, Universidade de Campinas, Campinas, 1993.

POLLARD, C.V.; RICHARDSON, C.R. Effects of organic chromium (bio-chrome) on growth, efficiency and carcass characteristics of feedlot steers. In: LYONS, T.P.; JACQUES, $\mathrm{K}$. (Eds.) Biotechnelogy in feedlot industry. 15.ed. Nottinghom: University Press, 1999. p.103-146.

PRADO, C.S.; PÁDUA, J.T.; CORREA, M.P.C. et al. Comparação de diferentes métodos de avaliação da área de olho de lombo e cobertura de gordura em bovinos de corte. Ciência Animal Brasileira, v.5, n.3, p.141-149, 2004.

RESTLE, J.; VAZ, F.N.; FEIJÓ, G.L.D. et al. Características de carcaça de bovinos de corte inteiros ou castrados de diferentes composições raciais Charolês x Nelore. Revista Brasileira de Zootecnia, v.29, n.5, p.1371-1379, 2000.

ROÇA, R.O. Tecnologia da carne e produtos derivados. 2.ed. Botucatu: Departamento de Gestão e Tecnologia Agroindustrial/ FCA/UNESP, 2001. 201p.

RODRIGUES, E. Crescimento dos tecidos muscular e adiposo e qualidade da carne de novilhas de diferentes grupos genéticos no modelo biológico supreprecoce. 2007. 67f. Dissertação (Mestrado em Zootecnia) Faculdade de Medicina Veterinária e Zootecnia, Universidade Estadual Paulista, Botucatu, 2007.

SANTOS, E.D.G.; PAULINO, M.F.; LANA, R.P. et al. Influência da suplementação com concentrado nas características de carcaça de bovinos F1 Limousin Nelore, não castrados, durante a seca, em pastagens. Revista Brasileira de Zootecnia, v.31, n.4, p.1823-1832, 2002. 
SILVA, S.L.; LEME, P.R.; PUTRINO, S.M. et al. Alterações nas características de carcaça de tourinhos Nelore, avaliados por ultrasom. Revista Brasileira de Zootecnia, v.35, n.2, p.607-612, 2006.

TAYLOR, R.E. Beef production and management: decisions. 2.ed. New Jersey: Prentice-Hall, 1994. 660p.

UNIVERSIDADE FEDERAL DE VIÇOSA - UFV. Sistema de análises estatísticas e genéticas - SAEG. Versão 8.0. Viçosa, MG: 2000. 142p.

WHEELER, T.L., SHACKELFORD, S.D.; JOHNSON, L.P. et al. A comparison of Warner- Bratzler shear force assessment within and among institutions. Journal of Animal Science, v.75, p.2423-2432, 1997.

ZANETTI, M.A.; SALLES, M.S.V.; BRISOLA, M.L. et al. Desempenho e resposta metabólica de bezerros recebendo dietas suplementadas com cromo. Revista Brasileira de Zootecnia. v.32, n.6, p.1532-1535, 2003.

ZERVOUDAKIS, J.T.; PAULINO, M.F.; DETMANN, E. et al. Desempenho e características de carcaça de novilhos suplementados no período das águas. Revista Brasileira de Zootecnia, v.30, n.4, p.1381-1389, 2001. 